\title{
Increased radon-222 in soil gas because of cumulative seismicity at active faults
}

\author{
Katsuaki Koike ${ }^{1 *}$, Tohru Yoshinaga ${ }^{2}$, Takayoshi Ueyama ${ }^{3}$ and Hisafumi Asaue ${ }^{4}$
}

\begin{abstract}
This study demonstrates how the radon-222 ( $\left.{ }^{222} \mathrm{Rn}\right)$ concentration of soil gas at an active fault is sensitive to cumulative recent seismicity by examining seven active faults in western Japan. The ${ }^{222} \mathrm{Rn}$ concentration was found to correlate well with the total earthquake energy within a 100-km radius of each fault. This phenomenon can probably be ascribed to the increase of pore pressure around the source depth of ${ }^{222} \mathrm{Rn}$ in shallow soil caused by frequently induced strain. This increase in pore pressure can enhance the ascent velocity of ${ }^{222} \mathrm{Rn}$ carrier gas as governed by Darcy's law. Anomalous ${ }^{222} \mathrm{Rn}$ concentrations are likely to originate from high gas velocities, rather than increased accumulations of parent nuclides. The high velocities also can yield unusual young gas under the radioactive nonequilibrium condition of short elapsed time since ${ }^{222} \mathrm{Rn}$ generation. The results suggest that ongoing seismicity in the vicinity of an active fault can cause accumulation of strain in shallow fault soils. Therefore, the ${ }^{222} \mathrm{Rn}$ concentration is a possible gauge for the degree of strain accumulation.
\end{abstract}

Keywords: Radon-222 concentration; Nonequilibrium condition; Gas velocity; Darcy's law; Total earthquake energy; Western Japan

\section{Findings} Introduction

Radon-222 $\left({ }^{222} \mathrm{Rn}\right)$ concentrations in soil gas and groundwater have been known to increase abruptly before and/or during large earthquakes in many parts of the world (Hauksson 1981; King 1984/85; Heinicke et al. 1995; Igarashi et al. 1995; Pérez et al. 2007; İnan et al. 2008; Kuo et al. 2010). The sensitivity of ${ }^{222} \mathrm{Rn}$ concentration has been confirmed by its response to earthquakes a few hundred kilometers away (Fleischer 1981; Toutain and Baubron 1999; Cicerone et al. 2009; Ghosh et al. 2009). ${ }^{222} \mathrm{Rn}$ is therefore thought to be a promising precursory gauge for large earthquakes. The observed spike-like increases in $\mathrm{Rn}$ concentration are similar to groundwaterlevel changes induced by earthquakes, and seismically enhanced crustal strain and pore pressure in saturated soils and rocks are the most plausible factors leading to this change (Manga et al. 2012).

Another widely recognized characteristic of ${ }^{222} \mathrm{Rn}$ is that concentrations tend to be high at faults (King 1978;

\footnotetext{
* Correspondence: koike.katsuaki.5x@kyoto-u.ac.jp

${ }^{1}$ Laboratory of Environmental Geosphere Engineering, Graduate School of

Engineering, Kyoto University, Katsura, Kyoto 615-8540, Japan

Full list of author information is available at the end of the article
}

King et al. 1996; Baubron et al. 2002; Walia et al. 2009; Neri et al. 2011). Therefore, ${ }^{222} \mathrm{Rn}$ surveys have been used to map faults and, in particular, to detect active faults. However, ${ }^{222} \mathrm{Rn}$ enhancement does not necessarily occur at all faults, and the mechanism for this enhancement is still disputed. Three possible causes are (i) the magnitude of fault displacement velocities during the late Quaternary, (ii) the accumulation of parent nuclides caused by historical large earthquakes, and (iii) recent seismicity at nearby faults. By undertaking a radioactivity survey at seven active fault areas in western Japan, this study aimed to identify the most rational cause of the ${ }^{222} \mathrm{Rn}$ concentration enhancement. The results could enable discrimination between faults that are continually active and faults that are occasionally active, i.e., faults experiencing stationary fracturing at short time scales or faults experiencing intermittent large fracturing over long time intervals.

\section{Fault description}

Seven active faults that have experienced historical and recent large earthquakes, the Atotsugawa (AT), Atera (AR), Nojima (NJ), Beppu-Haneyama (BH), Futagawa (FG), Hinagu (HN), and Izumi (IM), provide the data for this study. The hypocenters of earthquakes associated with

\section{它}


these faults from January 2001 to September 2010 are mostly located in the shallow crust at depths between 5 and $15 \mathrm{~km}$ at NJ, BH, FG, HN, and IM and at depths greater than $15 \mathrm{~km}$ at AT and AR (Figure 1). The density of earthquake epicenters is irregular and variable, even on the same fault, as can be seen clearly along HN. Earthquakes have been infrequent on $\mathrm{AR}, \mathrm{NJ}, \mathrm{BH}$, and IM. Activity ranks are defined by the average slip per thousand years: 1 to $10 \mathrm{~m}$ for rank $A$ and 0.1 to $1 \mathrm{~m}$ for rank B. Only AT and AR are evaluated as the most active rank A (The Research Group for Active Faults of Japan 1991). Table 1 provides a summary of the rank, length, movement pattern, radioactivity survey details, and surface geology for each fault. The lines shown in Figure 1 are perpendicular to fault strike (Figure 2). Surveys were undertaken on days without rain.

The latest large earthquakes and fault movements for the faults studied are well constrained by the evaluation reports of active faults (The Headquarters for Earthquake Research Promotion 2013). An 1858 earthquake (magnitude $M 7.0$ to 7.1 ) has been ascribed to movement of a portion of AT. The latest large earthquake on AR, which occurred in 1586, is thought to have been about $M$ 7.8. A destructive earthquake of $M 7.3$ occurred in January 1995 on the northern part of NJ at a depth of $16 \mathrm{~km}$. The most recent movements on $\mathrm{BH}$, which is composed of a set of normal sub-faults forming grabens in an active volcanic area, range from $3.9 \mathrm{ka}$ to the sixth century AD in the north and from after the thirteenth century $\mathrm{AD}$ in the south. The latest remarkable movements of FG, HN, and IM are estimated from trenching investigations to be in the ranges of 6.9 to $2.4 \mathrm{ka}, 8.4$ to $2.2 \mathrm{ka}$, and 7.3 to $2.4 \mathrm{ka}$, respectively. A large earthquake of $M 6.4$ in 1997 was located on the south end of IM, where many small earthquakes had occurred along two orthogonal segments (Figure 1). The IM-3 survey line was positioned in this zone.

\section{Methods of radioactivity survey}

Measurement lines were established near trench investigation sites (FG-1, HN-1, and IM-1 and IM-2), in concentrated epicenter zones (all AT lines, all BH lines, FG-2 and

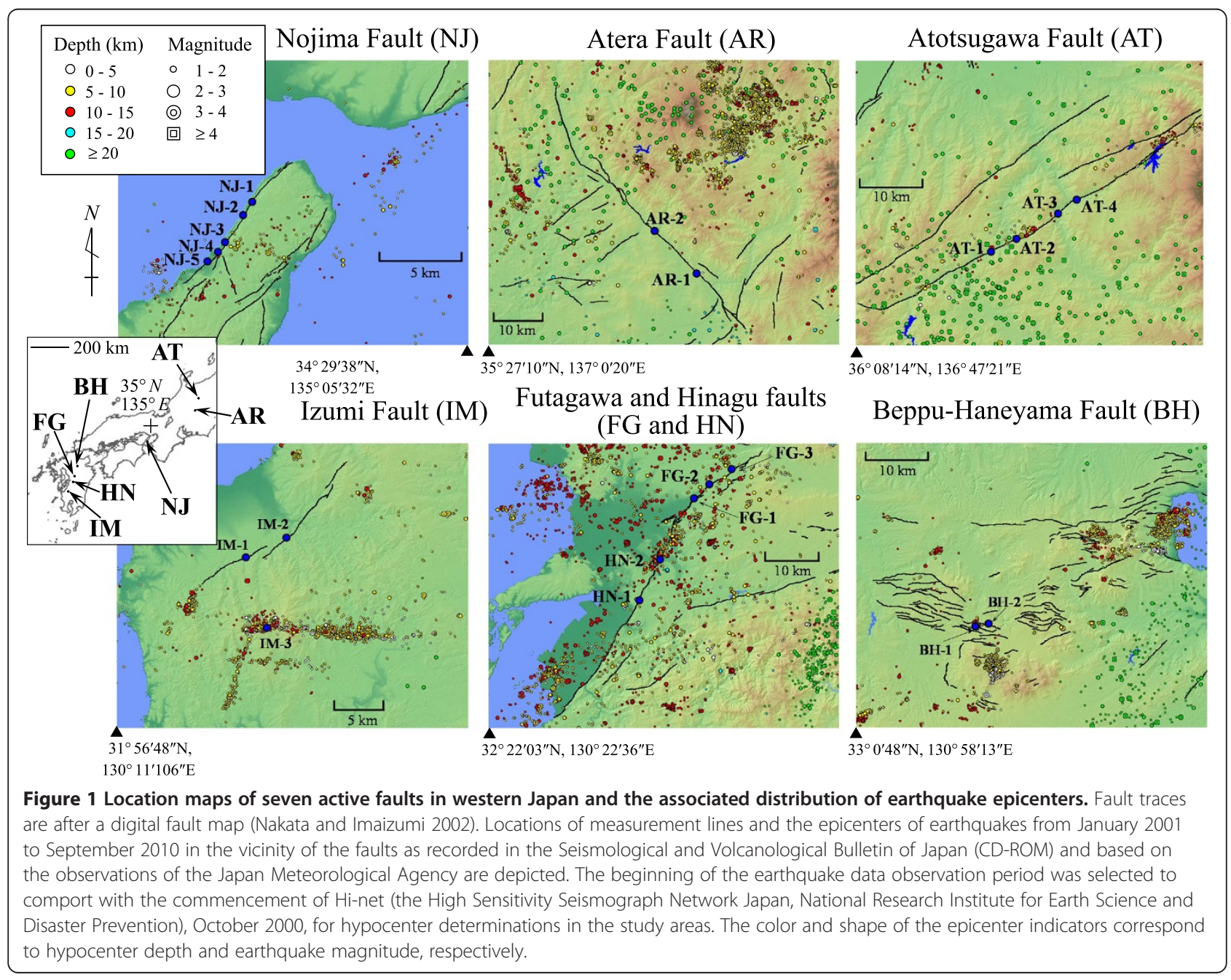


Table 1 Details of the active faults studied

\begin{tabular}{|c|c|c|c|c|c|c|c|}
\hline Fault name & Atotsugaw (AT) & Atera (AR) & Nojima (NJ) & $\begin{array}{c}\text { Beppu- } \\
\text { Haneyama (BH) }\end{array}$ & Futagawa (FG) & Hinagu (HN) & Izumi (IM) \\
\hline Rank of activity & $A$ & A & B & B & B & B & B \\
\hline Length $(\mathrm{km})$ & 70 & 66 & 15 & 30 to 40 & 29 & 70 & 20 \\
\hline $\begin{array}{l}\text { Movement } \\
\text { pattern }\end{array}$ & Right-lateral slip & $\begin{array}{l}\text { Left-lateral } \\
\text { slip }\end{array}$ & Right-lateral slip & $\begin{array}{l}\text { A set of E-W } \\
\text { normal } \\
\text { sub-faults }\end{array}$ & Right-lateral slip & $\begin{array}{l}\text { Right-lateral } \\
\text { slip }\end{array}$ & $\begin{array}{l}\text { Normal fault with } \\
\text { right-lateral slip }\end{array}$ \\
\hline Number of lines & 4 & 2 & 5 & 2 & 3 & 2 & 3 \\
\hline $\begin{array}{l}\text { Number of survey } \\
\text { points at each line }\end{array}$ & $\begin{array}{l}\text { AT-1 (9), AT-2 (5), } \\
\text { AT-3 (5), AT-4 (4) }\end{array}$ & $\begin{array}{l}\text { AR-1 (15), } \\
\text { AR-2 (13) }\end{array}$ & $\begin{array}{c}\text { NJ-1 (26), NJ-2 (12), } \\
\text { NJ-3 (7), NJ-4 (4), } \\
\text { NJ-5 (4) }\end{array}$ & $\begin{array}{l}\mathrm{BH}-1 \text { (9), } \\
\mathrm{BH}-2(8)\end{array}$ & $\begin{array}{c}\text { FG-1 }(10), \text { FG-2 (4), } \\
\text { FG-3 (7) }\end{array}$ & $\begin{array}{l}\mathrm{HN}-1(25) \\
\mathrm{HN}-2(33)\end{array}$ & $\begin{array}{l}\text { IM-1 (9), IM-2 } \\
(10), \mid \mathrm{IM}-3(11)\end{array}$ \\
\hline $\begin{array}{l}\text { Total survey } \\
\text { points }\end{array}$ & 23 & 28 & 53 & 17 & 21 & 58 & 30 \\
\hline $\begin{array}{l}\text { Number of soil } \\
\text { samples at each } \\
\text { line }\end{array}$ & AT-2 (2) & $\begin{array}{l}\text { AR-1 (10), } \\
\text { AR-2 (8) }\end{array}$ & $\begin{array}{c}\text { NJ-1 }(4), N J-2(3), \\
\text { NJ-3 (2), NJ-4 (1), } \\
\text { NJ-5 (2) }\end{array}$ & $\mathrm{BH}-1$ (9) & $\begin{array}{c}\text { FG-1 (10), FG-2 } \\
(4), F G-3(7)\end{array}$ & $\begin{array}{l}\mathrm{HN}-1 \text { (11), } \\
\mathrm{HN}-2(33)\end{array}$ & $\begin{array}{l}\text { IM-1 (8), IM-2 } \\
(3), I M-3(5)\end{array}$ \\
\hline Total soil samples & 2 & 18 & 12 & 9 & 21 & 44 & 16 \\
\hline Survey period & $\begin{array}{l}\text { Nov. to Dec. } \\
2008\end{array}$ & Dec. 2006 & Dec. 2007 & Dec. 2009 & $\begin{array}{l}\text { Oct. to Dec. } \\
2004\end{array}$ & $\begin{array}{l}\text { Oct. 2005, Jan. } \\
\text { and Oct. 2006, } \\
\text { Oct. } 2009\end{array}$ & Dec. 2010 \\
\hline Surface geology & M & $S$ & S & V & $S(F G-2), V$ & $\begin{array}{c}M(H N-1), V \\
(H N-2)\end{array}$ & $G(I M-3), S$ \\
\hline $\begin{array}{l}\text { Number of } \\
\text { nonequilibrium } \\
\text { points (\%) }\end{array}$ & $6(26)$ & $5(18)$ & $0(0)$ & $6(35)$ & $6(29)$ & $17(29)$ & $8(27)$ \\
\hline
\end{tabular}

FG-3, HN-2, and IM-3), near fault outcrops (all AR lines), and near the surface displaced by the latest large earthquake (all NJ lines). Survey points were placed at 1 - to 10 $\mathrm{m}$ intervals along a line or at 100- or 500-m intervals on a grid pattern applied to $\mathrm{HN}-2$ (Figure 2). Because it was difficult to identify the position of the Hinagu Fault in the flat terraced landscape of the $\mathrm{HN}-2$ area, the epicenters of $M \geq 2$ earthquakes were used to establish the survey points there. At each survey point, soil gas was sampled from a hole with a depth of $60 \mathrm{~cm}$ and a diameter of $3 \mathrm{~cm}$. The total number of $\alpha$ particles per minute $(\mathrm{cpm})$ resulting from the decay of ${ }^{222} \mathrm{Rn}$ and ${ }^{220} \mathrm{Rn}$ and their daughter nuclides, ${ }^{218} \mathrm{Po}$ and ${ }^{216} \mathrm{Po}$, were counted successively for 10 to $20 \mathrm{~min}$ using a portable $\alpha$-scintillation detector, RDA-200 (Scintrex, Vaughan, Canada) or AB-5 (Pylon Electrics, Ottawa, Canada). The long count time was used to ascertain whether the gas was at nonequilibrium or equilibrium when judgment was difficult.

To estimate the true ${ }^{222} \mathrm{Rn}$ concentration from the total cpm, the CRAS method (calculation method of numbers of $\mathrm{Rn}$ isotope atoms and their daughters at the start of measurement: Koike et al. 2009), which considers the radioactive equilibrium relationship between ${ }^{222} \mathrm{Rn}$ and ${ }^{218}$ Po in soil gas, was used. Numbers of ${ }^{222} \mathrm{Rn}\left(N_{222}\right)$,
${ }^{220} \mathrm{Rn},{ }^{218}$ Po, and ${ }^{216}$ Po were determined. Only $N_{222}$ was used to characterize the faults studied because the half-life of ${ }^{222} \mathrm{Rn}$ (3.823 days) is much longer than that of the other isotopes. One noteworthy feature is that the soil gases at $21 \%$ of the points exhibited nonequilibrium conditions, i.e., the cpm increased with time due to an increase in ${ }^{218}$ Po decays (Figure 3 ). This type of gas is young (i.e., not much time has elapsed after the generation of ${ }^{222} \mathrm{Rn}$ atoms) and observed typically in fumarole gases with high ascent velocities (Koike et al. 2009, 2014). Another feature is that the percentages of nonequilibrium points are similar for each fault except NJ (Table 1). The other gases exhibited equilibrium conditions in which the cpm mostly decreased in the first few minutes due to a decrease in decays of ${ }^{220} \mathrm{Rn}$ (half-life $53 \mathrm{~s}$; Figure 3), while the rates of decay of ${ }^{222} \mathrm{Rn}$ and ${ }^{218}$ Po remained constant. Usual soil gases show this cpm pattern. The predicted total decays agree well with the measurement data for both conditions (Figure 3), demonstrating the validity of the CRAS approach.

Soil samples were taken from the bottom of the borehole after the soil gas survey, dried at $80^{\circ} \mathrm{C}$ for $24 \mathrm{~h}$, and arranged for samples with particle sizes smaller than $0.25 \mathrm{~mm}$ and mass of $150 \mathrm{~g}$. A $\gamma$-ray spectrometer using 


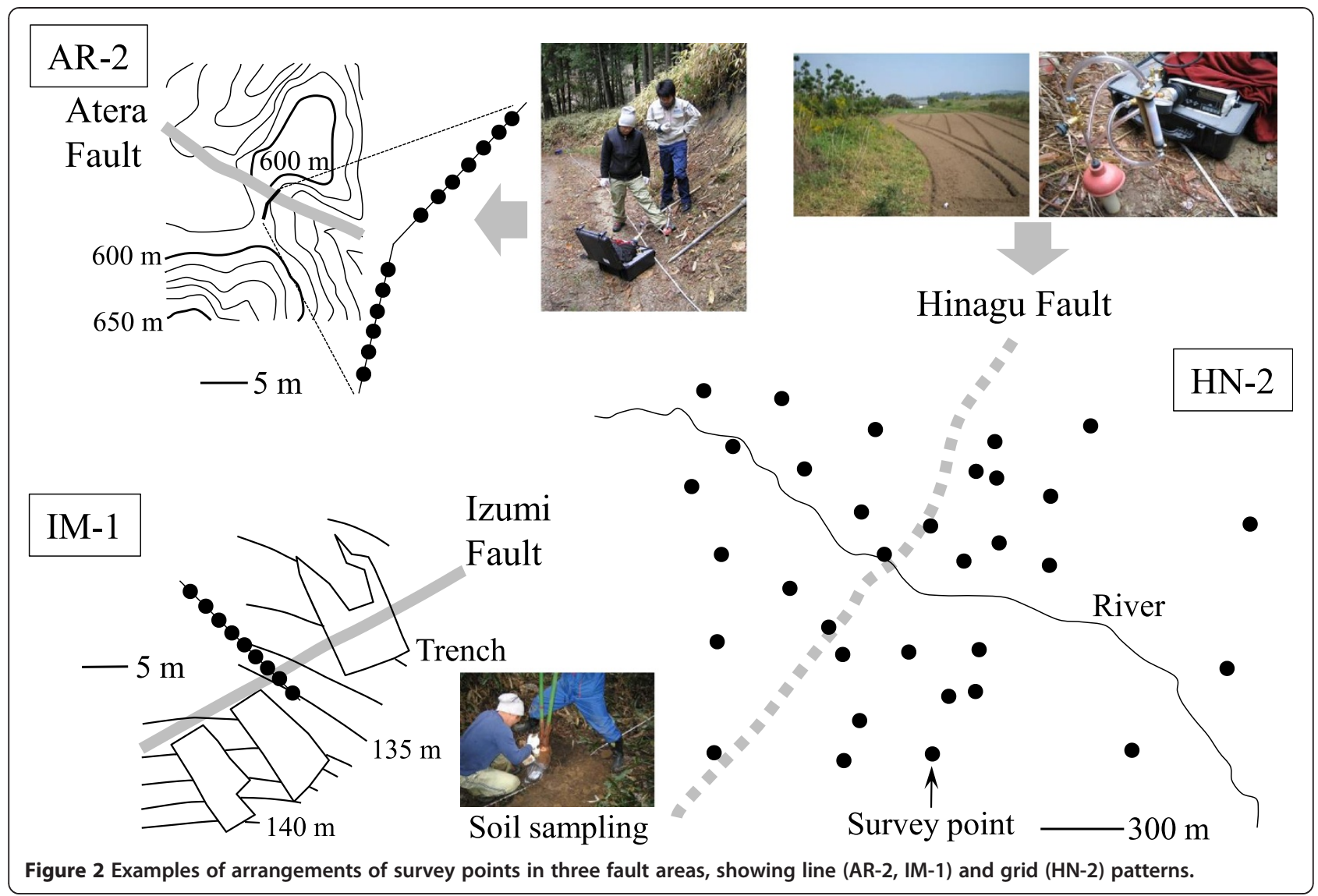

a Ge semiconductor detector (GMX-25190-P: EG\&G ORTEC, Oak Ridge, USA) was used to measure the $\gamma$ ray intensity (counts) of the $12 \gamma$-decay nuclides in the uranium and thorium series. The concentration of nuclides was assumed to be proportional to the $\gamma$-ray intensity. Only the $\gamma$-ray intensity of ${ }^{226} \mathrm{Ra}\left(I_{226} 122\right.$ data in total) was used in conjunction with $N_{222}$ (230 data in total) because of the isotope's long half-life (1,601 years) and because it is a direct parent nuclide of ${ }^{222} \mathrm{Rn}$. We used the conventional definition of $I_{226}$ in becquerels per gram from the original $\gamma$-ray channel data in counts by the following transformation. First, the net spectral peak count of ${ }^{226} \mathrm{Ra}$ per second was measured using Covell's method (Covell 1959), and then it was divided by three factors: the detector efficiency of ${ }^{226} \mathrm{Ra}(0.065 \%)$, sample weight $(\mathrm{g})$, and $\gamma$-ray yield from a standard source.

\section{Results and discussion}

\section{Identifying the controlling factor for ${ }^{222} R n$ concentration}

Because gas ascent velocity generally is slow in the study area, the ${ }^{222} \mathrm{Rn}$ source must be located in shallow soils. The average length by molecular diffusion of ${ }^{222} \mathrm{Rn}$ in soils, $L(\mathrm{~m})$, is given by a function of the diffusion coefficient, $D\left(\mathrm{~m}^{2} / \mathrm{s}\right)$, and decay constant, $\lambda_{222}\left(\mathrm{~s}^{-1}\right)$, as
$\sqrt{D / \lambda_{222}}$ (Lehmann et al. 2000). The assignment of a general value for dry soil, $D=5.0 \times 10^{-6} \mathrm{~m}^{2} / \mathrm{s}$ (Megumi and Mamuro 1973; Holford et al. 1993), derives $L=$ $1.6 \mathrm{~m}$. First, the values of $N_{222}$ and $I_{226}$ were analyzed from their relationship with the surface geology, which was classified roughly into granitic (G), volcanic (V), sedimentary $(\mathrm{S})$, and metamorphic $(\mathrm{M})$ rock types using the seamless digital geological map of Japan (Geological Survey of Japan 2013). The soils originated from weathering of these rocks. Summary statistics of the $N_{222}$ and $I_{226}$ data shown with box plots (Figure $4 \mathrm{a}, \mathrm{b}$ ) reveal that the magnitude orders by rock type of the upper quartile and median are the same $(G>V>S>M)$ in both cases. This implies that surface geology has some effect on the radioactive nuclide concentrations. However, focusing on the median values, the differences in the values are slight for both $N_{222}$ and $I_{226}$. Therefore, some other stronger factors must cause the large concentration variability.

A scattergram of the $N_{222}$ and $I_{226}$ data at the same points highlights the absence of a clear correlation (Figure 5: correlation coefficient $R=0.17)$. Such an absence also has been observed in other case studies (Ball et al. 1991; Cecil et al. 1991; Ioannides et al. 2003; Appleton et al. 2011). This feature is probably the result 


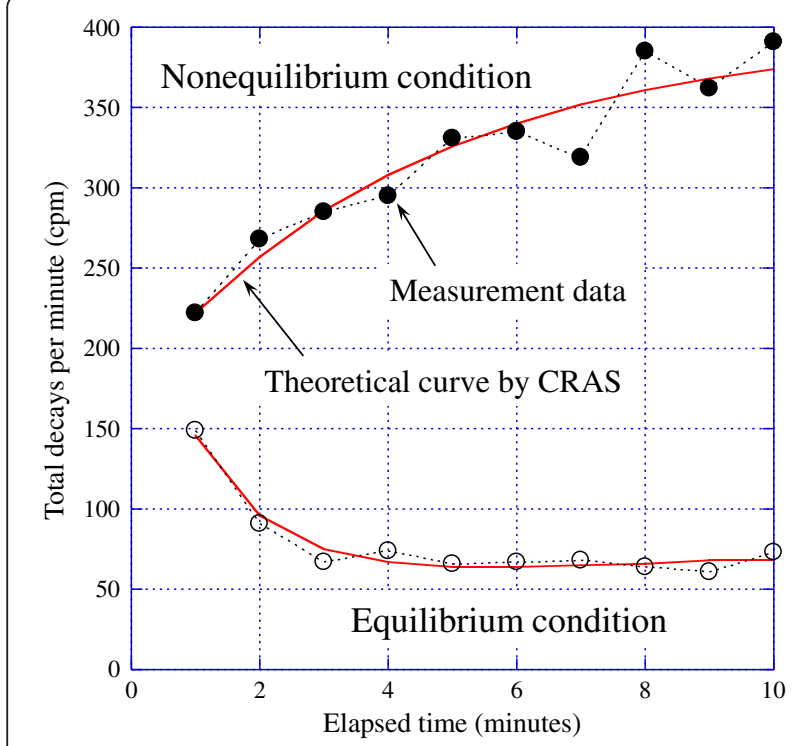

Figure 3 Total decay counts per minute. Typical patterns of total decay counts per minute in soil gas for ${ }^{222} \mathrm{Rn},{ }^{220} \mathrm{Rn}$, and their daughter nuclides, ${ }^{218} \mathrm{Po}$ and ${ }^{216} \mathrm{Po}$. Upper and lower curves represent the gases under radioactive nonequilibrium and equilibrium conditions, respectively. The solid line represents the CRAS (Koike et al. 2009) calculation, which agrees well with the measurement data denoted by circles. The upper and lower data were collected from survey points on lines FG-2 and HN-1 (Figure 1).

of the difference in state, i.e., gas $\left({ }^{222} \mathrm{Rn}\right)$ and solid $\left(\mathrm{z}^{226} \mathrm{Ra}\right)$. Accordingly, it is most pertinent to interpret that high ${ }^{222} \mathrm{Rn}$ concentrations do not originate from accumulated parent nuclides in soils but rather from the high ascent velocity of the carrier gas $(v)$. This interpretation is evidenced by the simple kinetic transport of ${ }^{222} \mathrm{Rn}$ in the vertical direction in shallow soils. The transport can be expressed by the following mass balance equation, which combines molecular diffusion and advection of the carrier gas flow (Kristiansson and Malmqvist 1982; Ioannides et al. 2003):

$$
\frac{\partial C_{222}(z)}{\partial t}=\phi-\lambda_{222} C(z)+\frac{D}{\varepsilon} \quad \frac{\partial^{2} C_{222}(z)}{\partial z^{2}}-v \frac{\partial C_{222}(z)}{\partial z}
$$

where $C_{222}(z)$ is the ${ }^{222} \mathrm{Rn}$ concentration at depth $z$ (positive downward from the surface), $\phi$ is the ${ }^{222} \mathrm{Rn}$ production rate per unit time, and $\varepsilon$ is the soil porosity. Under the steady state condition $\partial C_{222}(z) / \partial t=0$ and the ${ }^{222} \mathrm{Rn}$ concentration at the ground surface $C_{222}(z=0)=0$, a solution for the equation is the following (Kristiansson and Malmqvist 1982; Ioannides et al. 2003).

$$
C_{222}(z)=\frac{\phi}{\lambda_{222}}\left\{1-\exp \left[-\left(\sqrt{\left(\frac{\nu \varepsilon}{2 D}\right)^{2}+\frac{\lambda_{222} \varepsilon}{D}}+\frac{\nu \varepsilon}{2 D}\right) z\right]\right\}
$$

If we assume the equilibrium condition between ${ }^{222} \mathrm{Rn}$ and ${ }^{226} \mathrm{Ra}$, then $\lambda_{222} C_{222}(z)$ should be equal to $\lambda_{226} C_{226}$ $(z)$. It follows that $\phi=\lambda_{226} C_{226}(z)$, where $C_{226}(z)$ and $\lambda_{226}$ are the ${ }^{226} \mathrm{Ra}$ concentration at $z$ and the decay constant of ${ }^{226} \mathrm{Ra}$, respectively. $C_{222}(z)$ at $z=60 \mathrm{~cm}$ (the bottom depth of the borehole) is calculated by assigning the above value $D=5 \times 10^{-6} \mathrm{~m}^{2} / \mathrm{s}$ and a fixed $\varepsilon$ of 0.3 . In normal soils, $v$ is smaller than $1 \times 10^{-5} \mathrm{~m} / \mathrm{s}$ (Kristiansson and Malmqvist 1982; Schery and Siegel 1986). The value $1 \times 10^{-3} \mathrm{~m} / \mathrm{s}$ is its upper limit according to the study of Brown (2000). Using two values for high and low velocity, the ratio of $C_{222}(z)$ at $v=5 \times 10^{-5}$ and $5 \times$ $10^{-6}(\mathrm{~m} / \mathrm{s})$ is 3.1 for the same $C_{226}(z)$. This means that the ${ }^{222} \mathrm{Rn}$ concentration is highly variable by a factor of
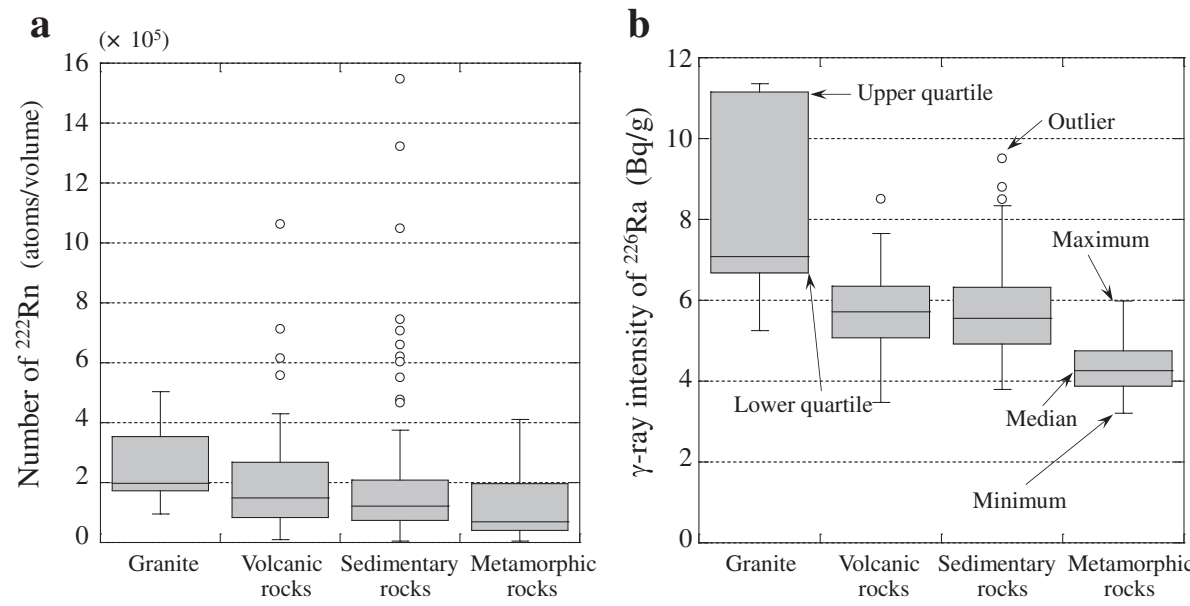

Figure 4 Summary statistics for the ${ }^{222} \mathrm{Rn}$ and ${ }^{226} \mathrm{Ra}$ data. Box plots show (a) the number of ${ }^{222} \mathrm{Rn}$ data and (b) the $\mathrm{\gamma}^{- \text {ray }}$ intensity of ${ }^{226} \mathrm{Ra}$ data classified by the rock type that weathered to form the shallow soils. 


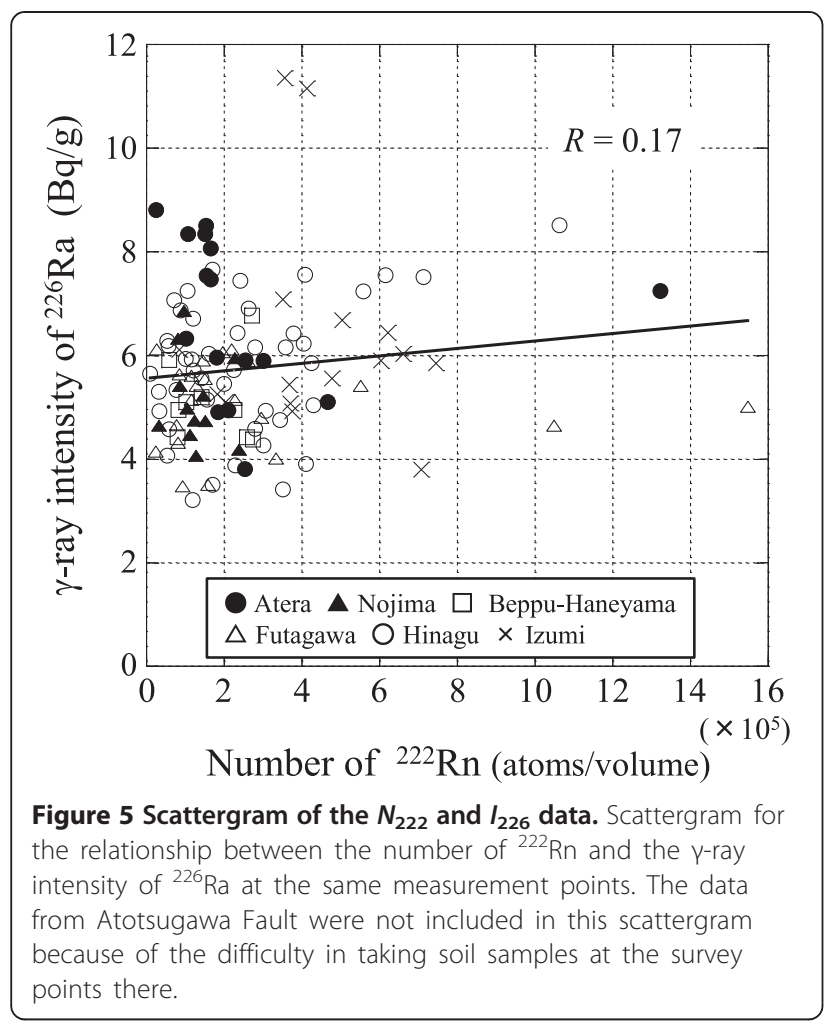

3 in this case even though the ${ }^{226} \mathrm{Ra}$ concentration is constant. For a pair of velocities with less contrast, $v=$ $5 \times 10^{-5}$ and $1 \times 10^{-5}(\mathrm{~m} / \mathrm{s})$, the ratio is 2.3. In loose deposits, $D$ ranges from $1.5 \times 10^{-6}$ to $6.8 \times 10^{-6} \mathrm{~m}^{2} / \mathrm{s}$ (Gasparini and Mantovani 1978). When $D$ is halved $\left(2.5 \times 10^{-6} \mathrm{~m}^{2} / \mathrm{s}\right)$, the ratios for the above two $v$ pairs become 2.4 and 1.7. Consequently, the absence of a correlation between ${ }^{222} \mathrm{Rn}$ and ${ }^{226} \mathrm{Ra}$ can be attributed to the changeability in gas ascent velocity in the soils, not to the heterogeneous distribution of ${ }^{226} \mathrm{Ra}$ concentration.

\section{Effect of earthquake energy and mechanism of ${ }^{222} \mathrm{Rn}$ enhancement}

Next, we evaluate the effect of earthquake energy, $E(\mathrm{~J})$, on $N_{222}$. $E(\mathrm{~J})$ is related to $M$ by the Gutenberg-Richter law, $\log E=1.5 M+4.8$ or $E=10^{1.5 M+4.8}$. Considering the attenuation of $E$ with distance from the hypocenter, $d$, the $E$ at $d$ per unit area was set to be proportional to the inverse of $d^{2}$, based on the spherical divergence of a seismic wave propagating in a homogeneous medium. In each active fault area, the distance from a measurement point location to a hypocenter was defined as $d$, and all $E / d^{2}$ values were summed. This summation is termed the total earthquake energy (TEE).

Among the earthquakes shown in Figure 1, those occurring within a circle of a given radius were selected to clarify the relationship between TEE and radius. Therefore, TEE is expressed as

$$
\mathrm{TEE}=\sum_{i=1}^{n} \frac{E_{i}}{d_{i}^{2}}
$$

where $n$ is the total number of earthquakes from January 2001 to September 2010 with $d \leq$ the radius. TEE essentially increases as the radius increases, but the TEE values of all faults converge at a radius of approximately $100 \mathrm{~km}$ (Figure 6a). The ${ }^{222} \mathrm{Rn}$ concentration anomaly can occur at an epicentral distance of $100 \mathrm{~km}$ for an approximately M 4.7 earthquake and a crustal strain of $10^{-8}$ from an empirical relationship derived by using worldwide earthquake data (Fleischer 1981; Toutain and Baubron 1999). Thus, TEE for each fault area was defined by this radius. Because the $N_{222}$ values are dispersed widely, which is common to all faults, their median value was used for characterizing TEE. The median values have an obviously strong positive correlation with TEE $(R=0.97)$, as shown by the regression line in Figure 6b. It is proved, therefore, that the ${ }^{222} \mathrm{Rn}$ concentration in an active fault area is affected by the summation of recent earthquakes within a $100-\mathrm{km}$ radius. Our findings show that for an active fault with historically large earthquakes but no recent seismicity, the ${ }^{222} \mathrm{Rn}$ concentration will tend to be low, as evidenced by the case of AT.

The effect of the length of time on TEE was examined by fixing the radius at $100 \mathrm{~km}$ and using 10 periods from 2 to 20 years with 2 -year intervals. The $R$ values between TEE and the median of the $N_{222}$ values for the seven faults were calculated for each time period. As shown in Figure 7, the values approximately show a convex curve: $R$ increases as the period becomes longer, reaches a peak at the 10-year period, and then decreases toward the 20year period. Thus, the TEE analysis indicates that the 10-year period from January 2001 to September 2010 is the most suitable.

The mechanism causing the strong correlation described above can be interpreted by a simplified dislocation model (Fleischer 1981). This model assumes the Earth to be an infinite isotropic elastic solid containing a circular dislocation loop of radius $r$ and slip vector $b$. As long as the ratio $r / b$ is constant, the shear strain change $\Delta \gamma$ at $d$ can be related to $M$ as $\Delta \gamma \propto 10^{1.44 M} / d^{3}$. For the same $d$, this equation derives $\Delta \gamma \propto 10^{M}$ and, further, $\Delta \gamma \propto E$ from the Gutenberg-Richter law. Therefore, the shear strain change becomes proportional to the earthquake energy, and the increase in strain causes a corresponding increase in stress, $\Delta \sigma$.

In shallow soils, the carrier gas velocity of ${ }^{222} \mathrm{Rn}$ (the above $v$ ) is thought to be governed by Darcy's law (Kristiansson and Malmqvist 1982; Schery and Siegel 1986; Ioannides et al. 2003). Assuming that the intrinsic 


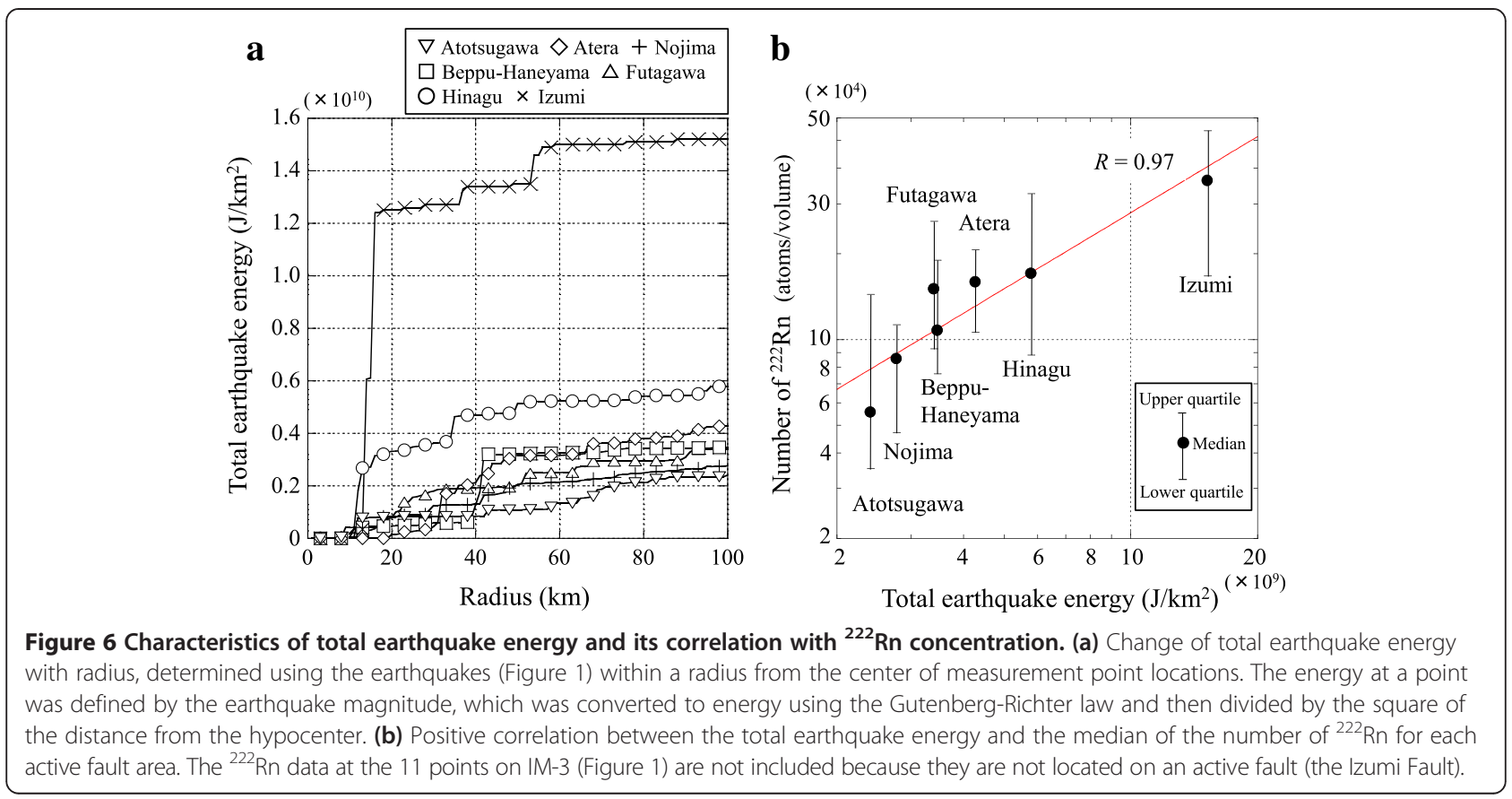

permeability of soil and gas viscosity are constant with time and the gas flow is laminar with Reynolds number $<1$, then $v$ becomes proportional to the pressure gradient, $v \propto \partial p / \partial z$. If the gradient is constant over the depth range, then $v$ can be further simplified as $v \propto p(s)-p(g)$, where $p(s)$ and $p(g)$ denote the pore pressures at the ${ }^{222} \mathrm{Rn}$ source depth (the maximum depth from which ${ }^{222} \mathrm{Rn}$ can reach the detector)

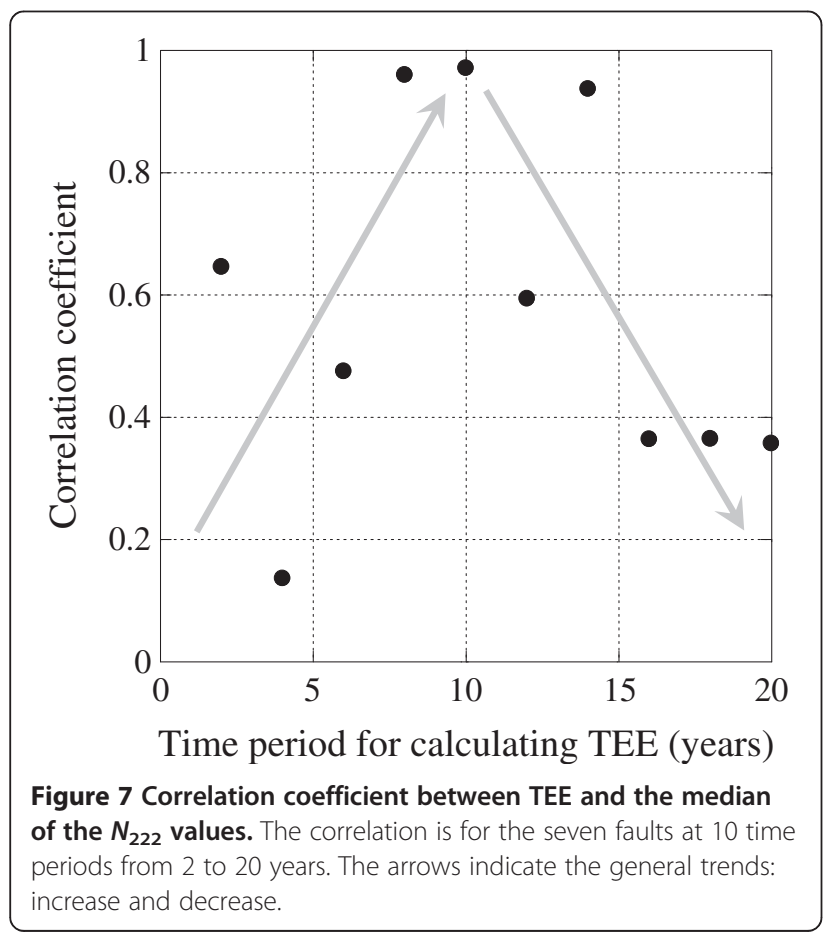

and the ground surface, respectively; $p(g)$ is almost constant ( $=1 \mathrm{~atm})$ despite small fluctuations with weather conditions, and $p(s)$ is variable. It is reasonable to consider that the $\Delta \sigma$ can enhance $p(s)$. This enhancement induces an increase in $v$ and consequently an increase in ${ }^{222} \mathrm{Rn}$ concentration because of the sensitivity of the concentration to $v$. At active fault areas with many recent earthquakes (e.g., $\mathrm{IM}, \mathrm{HN}$, and $\mathrm{AR}), p(s)$ is considered to be at a higher level than in inactive seismic areas because of frequent ground motions that enhance strain and stress. Additionally, the motions may have generated preferred pathways in shallow soils for the carrier gas, such as cracks and connections between pores. This pathway generation can also enhance $v$ and cause a nonequilibrium condition of soil gas. These states essentially enhance ${ }^{222} \mathrm{Rn}$ concentration without the accumulation of ${ }^{226} \mathrm{Ra}$.

\section{Conclusion}

Through the radioactivity survey at seven active fault areas in western Japan and the data analyses, three points were clarified by this study: the radioactive equilibrium condition for soil gas, the reason for enhanced ${ }^{222} \mathrm{Rn}$ concentrations in soil gas, and the differences in ${ }^{222} \mathrm{Rn}$ concentrations in soil gas associated with active faults. The cause of the nonequilibrium gas patterns at $21 \%$ of the points, indicating young gas of short elapsed time since ${ }^{222} \mathrm{Rn}$ generation, was interpreted as high ascent velocity of ${ }^{222} \mathrm{Rn}$ carrier gas. Therefore, the radioactive equilibrium condition of the soil gas can help to specify the locations at which the formation of passages along which the gas can ascend rapidly has occurred. 
The high velocity can generate anomalous ${ }^{222} \mathrm{Rn}$ concentrations without accumulations of its parent nuclides.

A new finding of this study is that the observed concentrations are correlated with the summation of recent earthquake energy within a $100-\mathrm{km}$ radius of the fault. From Darcy's law and the dislocation model, this phenomenon was interpreted by the increase of pore pressure around the source depth of ${ }^{222} \mathrm{Rn}$ in shallow soils caused by frequently induced strain. The increase in pore pressure can enhance the gas ascent velocity and, consequently, the ${ }^{222} \mathrm{Rn}$ concentration. This correlation suggests that terrestrial gas is sensitive to small changes in strain. Despite being associated with typical active faults with historically large earthquakes, the ${ }^{222} \mathrm{Rn}$ concentrations measured at the study sites in Japan are not necessary high if they are not accompanied by recent seismicity. Carrier gas velocity is the dominant factor affecting concentration.

In conclusion, ${ }^{222} \mathrm{Rn}$ concentration in an active fault area, in addition to being an earthquake precursor, acts as a capable gauge for evaluating the conditions of steady seismicity and strain accumulation around the fault. The ${ }^{222} \mathrm{Rn}$ concentration may contribute to the identification of regions within which the crust is repeatedly ruptured.

\section{Competing interests}

The authors declare that they have no competing interests.

\section{Authors' contributions}

KK designed the research plan, led the development of this study, and wrote the manuscript with contributions from TY, TU, and HA. TY was responsible for all radioactive surveys and sample analyses. TU contributed to the data analyses, mechanism clarification, and some of the surveys. HA assisted with the surveys, data analyses, and interpretations. All authors read and approved the final manuscript.

\section{Acknowledgements}

The authors wish to express their gratitude to the graduate students, who gave devoted assistance in this study, from the geophysical prospecting laboratory of Kumamoto University, Emeritus Professor Michito Ohmi of Kumamoto University for his cordial instructions, and Mr. Jitsuya Uemura of the Radioisotope Center of Kumamoto University for the instruction regarding the measurement of $\gamma$-ray spectra. Sincere thanks are extended to Dr. Kenji Amano, Dr. Masakazu Niwa, and Dr. Koji Shimada of JAEA for their cooperation with the field surveys at the Atotsugawa and Atera faults and to two anonymous reviewers for their valuable comments and suggestions that helped improve the clarity of the manuscript.

\section{Author details}

${ }^{1}$ Laboratory of Environmental Geosphere Engineering, Graduate School of Engineering, Kyoto University, Katsura, Kyoto 615-8540, Japan. ${ }^{2}$ Technical Division, Faculty of Engineering, Kumamoto University, Kumamoto 860-8555, Japan. ${ }^{3}$ Nippon Geophysical Prospecting Co., Ltd., Tokyo 143-0027, Japan. ${ }^{4}$ Graduate School of Science and Technology, Kumamoto University, Kumamoto 860-8555, Japan.

\section{Received: 25 November 2013 Accepted: 26 May 2014} Published: 17 June 2014

\section{References}

Appleton JD, Cave MR, Miles JCH, Sumerling TJ (2011) Soil radium, soil gas radon and indoor radon empirical relationships to assist in post-closure impact assessment related to near-surface radioactive waste disposal. J Environ Radioactivity 102:221-234, doi:10.1016/j.jenvrad.2010.09.007
Ball TK, Cameron DG, Colman TB, Roberts PD (1991) Behaviour of radon in the geological environment: a review. Q J Eng Geol 24:169-182, doi:10.1144/GSL. QJEG.1991.024.02.01

Baubron JC, Rigo A, Toutain JP (2002) Soil gas profiles as a tool to characterize active tectonic areas: the jaut pass example (Pyrenees, France). Earth Planet Sci Lett 196:69-81, doi:10.1016/S0012-821X(01)00596-9

Brown A (2000) Evaluation of possible gas microseepage mechanisms. AAPG Bull 84:1775-1789, doi:10.1306/8626C389-173B-11D7-8645000102C1865D

Cecil LD, Senior LA, Vogel KL (1991) Radium-226, radium-228, and radon-222 in ground water of the Chickies Quartzite, southeastern Pennsylvania. In: Gundersen LCS, Wanty RB (eds) Field studies of radon in rocks, soils, and water. Smoley, Florida, pp 267-277

Cicerone RD, Ebel JE, Britton J (2009) A systematic compilation of earthquake precursors. Tectonophysics 476:371-396, doi:10.1016/j.tecto.2009.06.008

Covell DF (1959) Determination of gamma-ray abundance directly from total absorption peak. Anal Chem 31:1785-1790, doi:10.1021/ac60155a027

Fleischer RL (1981) Dislocation model for radon response to distant earthquakes. Geophys Res Lett 8:477-480, doi:10.1029/GL008i005p00477

Gasparini P, Mantovani MSM (1978) Radon anomalies and volcanic eruptions. J Volcanol Geoth Res 3:325-341, doi:10.1016/0377-0273(78)90042-2

Geological Survey of Japan (2013) Seamless digital geological map of Japan (1:200,000). https://gbank.gsj.jp/seamless/maps.html. Accessed 31 Aug 2013

Ghosh D, Deb A, Sengupta R (2009) Anomalous radon emission as precursor of earthquake. J Appl Geophys 69:67-81, doi:10.1016/j.jappgeo.2009.06.001

Hauksson E (1981) Radon content of groundwater as an earthquake precursor: evaluation of worldwide data and physical basis. J Geophys Res 86:9397-9410, doi:10.1029/JB086iB10p09397

Heinicke J, Koch U, Martinelli G (1995) $\mathrm{CO}_{2}$ and radon measurements in the Vogtland area (Germany) - a contribution to earthquake prediction research. Geophys Res Lett 22:771-774, doi:10.1029/94GL03074

Holford D, Schery SD, Wilson JL, Phillips FM (1993) Modeling radon transport in dry, cracked soil. J Geophys Res 98:567-580, doi:10.1029/92JB01845

Igarashi G, Saeki S, Takahata N, Sumikawa K, Tasaka S, Sasaki Y, Takahashi M, Sano Y (1995) Ground-water radon anomaly before the Kobe earthquake in Japan. Science 269:60-61, doi:10.1126/science.269.5220.60

Inan S, Akgül E, Seyis C, Saatçılar R, Baykut S, Ergintav S, Baş M (2008) Geochemical monitoring in the Marmara region (NW Turkey): a search for precursors of seismic activity. J Geophys Res 113, B03401, doi:10.1029/2007JB005206

loannides K, Papachristodouloua C, Stamoulisa K, Karamanisa D, Pavlidesb S, Chatzipetrosb A, Karakalab E (2003) Soil gas radon: a tool for exploring active fault zones. Appl Radiat Isotopes 59:205-213, doi:10.1016/S0969-8043(03)00164-7

King C-Y (1978) Radon emanation on San Andreas fault. Nature 271:516-519, doi:10.1038/271516a0

King CY (1984/85) Impulsive radon emanation on a creeping segment of the San Andreas Fault, California. Pure Appl Geophys 122:340-352, doi:10.1007/BF00874603

King C-Y, King B-S, Evans WC, Zhang W (1996) Spatial radon anomalies on active faults in California. Appl Geochem 11:497-510, doi:10.1016/0883-2927 (96)00003-0

Koike K, Yoshinaga T, Asaue H (2009) Radon concentrations in soil gas considering radioactive equilibrium conditions with application to estimating fault-zone geometry. Environ Geol 56:1533-1549, doi:10.1007/s00254-008-1252-x

Koike K, Yoshinaga T, Asaue H (2014) Characterizing long-term radon concentration changes in a geothermal area for correlation with volcanic earthquakes and reservoir temperatures: a case study from Mt. Aso, southwestern Japan. J Volcanol Geoth Res 275:85-102, doi:10.1016/j.jvolgeores.2014.02.007

Kristiansson K, Malmqvist L (1982) Evidence for nondiffusive transport of ${ }_{86}^{222} \mathrm{Rn}$ in the ground and a new physical model for the transport. Geophysics 47:1444-1452, doi:10.1190/1.1441293

Kuo T, Su C, Chang C, Lin C, Cheng W, Liang H, Lewis C, Chiang C (2010) Application of recurrent radon precursors for forecasting large earthquakes $\left(M_{w}>6.0\right)$ near Antung, Taiwan. Radiat Meas 45:1049-1054, doi:10.1016/j. radmeas.2010.08.009

Lehmann BE, Lehmann M, Neffel A, Tarakanov SV (2000) Radon-222 monitoring of soil diffusivity. Geophys Res Lett 27:3917-3920, doi:10.1029/1999GL008469

Manga M, Beresnev I, Brodsky EE, Elkhoury JE, Elsworth D, Ingebritsen SE, Mays DC, Wang C (2012) Changes in permeability caused by transient stresses: field observations, experiments, and mechanisms. Rev Geophys 50, RG2004, doi:10.1029/2011RG000382 
Megumi K, Mamuro T (1973) Emanation and exhalation of radon and thoron gases from soil particles. J Geophys Res 79:3357-3360, doi:10.1029/ JB079i023p03357

Nakata T, Imaizumi T (eds) (2002) Digital active fault map of Japan. University of Tokyo Press, Tokyo (in Japanese)

Neri M, Giammanco S, Ferrera E, Patanè G, Zanon V (2011) Spatial distribution of soil radon as a tool to recognize active faulting on an active volcano: the example of Mt. Etna (Italy). J Environ Radioactivity 102:863-870, doi:10.1016/j.jenvrad.2011.05.002

Pérez NM, Hernández PA, Padrón E, Melián G, Marrero R, Padilla G, Barrancos J, Nolasco D (2007) Precursory subsurface ${ }^{222} \mathrm{Rn}$ and ${ }^{220} \mathrm{Rn}$ degassing signatures of the 2004 seismic crisis at Tenerife, Canary Islands. Pure Appl Geophys 164:2431-2448, doi:10.1007/s00024-007-0280-x

Schery SD, Siegel D (1986) The role of channels in the transport of radon from the soil. J Geophys Res 81:12,366-12,374, doi:10.1029/JB091iB12p12366

The Headquarters for Earthquake Research Promotion (2013) Evaluation of earthquakes, evaluations of active faults to date. http://www.jishin.go.jp/ main/p_hyoka02_danso.htm. Accessed 31 Aug 2013

The Research Group for Active Faults of Japan (1991) Active faults in Japan (revised edition). University of Tokyo Press, Tokyo, in Japanese with English abs

Toutain J-P, Baubron J-C (1999) Gas geochemistry and seismotectonics: a review. Tectonophysics 304:1-27, doi:10.1016/50040-1951(98)00295-9

Walia V, Yang TF, Hong W-L, Lin S-J, Fu C-C, Wen K-L, Chen C-H (2009) Geochemical variation of soil-gas composition for fault trace and earthquake precursory studies along the Hsincheng fault in NW Taiwan. Appl Radiat Isotopes 67:1855-1863, doi:10.1016/j.apradiso.2009.07.004

doi:10.1186/1880-5981-66-57

Cite this article as: Koike et al:: Increased radon-222 in soil gas because of cumulative seismicity at active faults. Earth, Planets and Space 2014 66:57.

\section{Submit your manuscript to a SpringerOpen ${ }^{\circ}$ journal and benefit from:}

- Convenient online submission

- Rigorous peer review

- Immediate publication on acceptance

- Open access: articles freely available online

- High visibility within the field

- Retaining the copyright to your article

Submit your next manuscript at $\gg$ springeropen.com 